Our current approach is to obtain a tissue diagnosis for all right-sided tumors thought to be malignant and as many left-sided tumors as reasonable (often from metastatic sites). If these are found to be primary cardiac sarcoma, we begin systemic treatment with doxorubicin-ifosfamide combination chemotherapy. Patients are followed up closely with functional (positron emission tomography and computed tomography) and structural (cardiac magnet resonance imaging) imaging every 2 cycles ( 6 weeks), and treatment is continued as long as the tumor continues to respond or until the patient is no longer tolerating chemotherapy. Most commonly, patients reach maximal response and early signs of significant toxicity by 6 cycles of chemotherapy. Our early worry that chemotherapy to this extent might increase surgical risks was found not to be true, and in addition this practice doubled our negative margin rate at surgery as well as our survival. ${ }^{3}$ Surgical resection is considered only after review by the multidisciplinary cardiac tumor review board.

The goal of surgery is complete resection, with negative margins and maintenance of good cardiac function. Advanced surgical techniques such as cardiac autotransplanation are often needed to achieve this goal, making referral to a reference center for this disease desirable. ${ }^{4}$ Even in patients with negative margins, we consider this a systemic disease and recommend adjuvant chemotherapy because of the high rates of metastatic disease. This practice was previously seen to be beneficial by Putnam and colleagues, and it is encouraging to see that Hendriksen and colleagues ${ }^{1}$ found the same outcome. We generally do not use radiotherapy unless we have local tumor issues outside the heart or we have decided that further cardiac resection is not possible.

We congratulate Hendriksen and colleagues ${ }^{1}$ on an excellent study and thank them for their addition to our current knowledge. Our patients will benefit from this, as will our field.

\section{References}

1. Hendriksen BS, Stahl KA, Hollenbeak CS, Taylor MD, Vasekar MK Drabick JJ, et al. Postoperative chemotherapy and radiation improve survival following cardiac sarcoma resection. J Thorac Cardiovasc Surg. 2021;161: 110-9.e4.

2. Ramlawi B, Leja MJ, Abu Saleh WK, Al Jabbari O, Benjamin R, Ravi V, et al. Sur gical treatment of primary cardiac sarcomas: review of a single-institution experience. Ann Thorac Surg. 2016;101:698-702.

3. Abu Saleh WK, Ramlawi B, Shapira OM, Al Jabbari O, Ravi V, Benjamin R, et al Improved outcomes with the evolution of a neoadjuvant chemotherapy approach to right heart sarcoma. Ann Thorac Surg. 2017;104:90-6.

4. Ramlawi B, Al-Jabbari O, Blau LN, Davies MG, Bruckner BA, Blackmon SH, et al. Autotransplantation for the resection of complex left heart tumors. Ann Thorac Surg. 2014;98:863-8.

5. Putnam JB Jr, Sweeney MS, Colon R, Lanza LA, Frazier OH, Cooley DA. Primary cardiac sarcomas. Ann Thorac Surg. 1991;51:906-10.

\title{
Commentary: Adjuvant therapy for cardiac sarcomas: Slowly evolving beyond resection
}

\author{
Joe B. Putnam, Jr, MD, FACS
}

Cardiac sarcomas are rare neoplasms with limited survival. Initial presentation can range from nondescript to life-threatening symptoms. Complete resection is

\footnotetext{
From the Baptist MD Anderson Cancer Center, Jacksonville, Fla.

Disclosures: Author has nothing to disclose with regard to commercial support.

Received for publication Nov 4, 2019; revisions received Nov 4, 2019; accepted for publication Nov 5, 2019; available ahead of print Nov 28, 2019.

Address for reprints: Joe B. Putnam, Jr, MD, FACS, Baptist MD Anderson Cancer Center, 1301 Palm Ave, Jacksonville, FL 32207 (E-mail: bill.putnam@bmcjax. com).

J Thorac Cardiovasc Surg 2021;161:121-2

$0022-5223 / \$ 36.00$

Copyright (C) 2019 by The American Association for Thoracic Surgery

https://doi.org/10.1016/j.jtcvs.2019.11.032
}

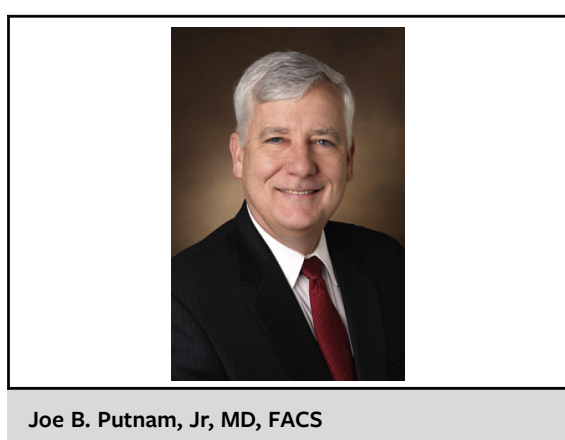

CENTRAL MESSAGE

Survival following resection for cardiac sarcoma may be improved with adjuvant therapy for up to 2 years compared with no adjuvant therapy or other nonsurgical care. 
recommended. ${ }^{1}$ Few physicians or institutions have sufficient experience to manage these patients consistently. However, the management challenge comes in part from obtaining the diagnosis before resection, achieving complete resection (R0), and selecting and sequencing additional therapies. In a large single-institution series, neoadjuvant chemotherapy before resection has been recommended to reduce the size of the tumor and enhance the potential for $\mathrm{R} 0$ resection.

In this edition of the Journal, Hendriksen and colleagues ${ }^{2}$ review the contemporary management of cardiac sarcomas treated with surgery, without surgery, and with surgery plus adjuvant therapy (AT). A review of the National Cancer Database (NCDB) identified 617 patients between 2004 and 2015 with cardiac sarcomas, predominately angiosarcoma $(48 \%)$, which is associated with poor survival. The NCDB includes $>70 \%$ of all newly diagnosed cancer cases nationally and contains $>34$ million historical records. The type and duration of AT was not controlled, and neoadjuvant therapy was not examined.

In the cohort of 617 patients, $60 \%$ were treated surgically, $25 \%$ were treated nonsurgically, and $15 \%$ received no treatment. Overall survival (OS) was poor (median, 11 months; 5-year OS, 9.5\%). Chemotherapy or chemoradiotherapy was chosen for AT in $>90 \%$ of patients receiving any AT. Patients who received surgery + AT had a median survival of 19 months, compared with 8 months for surgery alone. Approximately $25 \%$ of patients had an R0 resection documented, and $75 \%$ had $\mathrm{R} 1$, R2, or unknown resection classification. The 30-day mortality was $14 \%$ with surgery alone versus $3 \%$ for surgery plus AT, and 90-day mortality was $22 \%$ and $29 \%$, respectively. Although a trend toward improved survival $(P=.058)$ following resection in patients with metastatic disease was identified, resection may have better results in those patients with control of both the primary tumor and metastases.

The role of AT following resection is less clear. Two-year survival was improved for patients receiving surgery plus AT, but that survival advantage was lost thereafter. Were these patients more fit to receive AT or have less disease burden and thus achieved better survival? Or did the use of AT change the biology of this disease in some manner?

Although surgery and surgery plus AT are associated with better survival than no surgery for the first 2 years, perioperative mortality remains high. Even though survival was improved over the initial 2-year period following resection, embracing any operation with $22 \%$ to $29 \%$ mortality at 90 days needs to be carefully considered.

Additional surgeon and institutional experience are needed to improve survival more broadly. Complete resection (R0) should be a prime objective for each patient, yet resection alone is unlikely to be sufficient. In the absence of clinical trials, or therapy of demonstrated greater effectiveness, AT following R0 resection of cardiac sarcomas would be recommended. Neoadjuvant therapy based on a large single-center experience could also be considered. Obviously additional and better therapy is needed. Until then, patient selection should be "pragmatic and selective...given the high mortality, high rate of incomplete resections, and limited survival for this biologically complicated cancer."

\section{References}

1. Ramlawi B, Leja MJ, Abu Saleh WK, Al Jabbari O, Benjamin R, Ravi V, et al. Surgical treatment of primary cardiac sarcomas: review of a single-institution experience. Ann Thorac Surg. 2016;101:698-702.

2. Hendricksen BS, Stahl KA, Hollenbeak CS, Taylor MD, Vasekar MK, Drabick JJ, et al. Postoperative chemotherapy and radiation improve survival following cardiac sarcoma resection. J Thorac Cardiovasc Surg. 2021;161:110-9.e4. 